\title{
4. Parallelism in Duna Pikono
}

\author{
Michael Sollis
}

\section{Introduction}

This chapter builds upon the previous two by examining how parallelism occurs between musical elements and linguistic elements in a performance of Duna pikono. In chapter 2, Kenny Kendoli describes the significance of pikono in Duna culture. Kirsty Gillespie and Lila San Roque provide a detailed analysis of the musical and linguistic form of pikono in chapter 3. In this chapter I focus on parallelism in a particular performance of pikono by Kiale Yokona in 2005 which was recorded by Gillespie and linguistically transcribed by Lila San Roque.

Firstly, I will introduce Roman Jakobson's concept of parallelism as a way of understanding the interaction between musical and lingual elements in a sung performance. Secondly, I will show how parallelism operates with respect to either lingual elements or musical elements in Kiale's pikono. Thirdly, I will show two different ways in which parallelism operates between lingual elements and musical elements in Kiale's pikono. It is hoped that such a study will exemplify how parallelism operates with respect to musical elements and lingual elements in sung performances generally. ${ }^{1}$

\section{The concept of parallelism as an analytical tool}

Roman Jakobson's formulation of the poetic function and description of parallelism in linguistics (1960) provides a powerful tool for bridging the gap between musical and linguistic aspects of song. ${ }^{2}$ Jakobson describes the poetic function as being directed towards the message of a speech act (ibid.:356) and says that it "projects the principle of equivalence from the axis of selection into the axis of combination" (ibid.:358, italics in original). The poetic function allows a speaker to select a paradigmatic unit such as a word (the linguistic principle of selection) and place it into combination with other linguistic elements (the linguistic principle of combination) which are drawn from the same paradigmatic set, thus displaying their paradigmatic relatedness (or in Jakobson's terms, their "equivalence") along the syntagmatic axis. For example, Jakobson considers Caesar's victory message "Veni, vidi, vici" (I came, I saw, I conquered). Words are selected which are paradigmatically related in that all are verb

1 This paper comes out of a broader investigation into the relationship between music and language in Duna pikono (Sollis 2007).

2 Ruwet (1987) also invokes Jakobson in a musical analysis, but only in regards to semiotics. Feld (1988:75)

lists Jakobson in a summary of perspectives on style which can be applied to music. 
forms of the same grammatical class: first person singular past indicative. Furthermore, the three words are phonetically very similar, all starting with $v$, having two syllables, and ending with the vowel $i$. The concept of poetic function explains the process of creating Caesar's victory message (through the projection of paradigmatic units) and explains the realization of Caesar's victory message as a poetic form. Jakobson broadens the concept and suggests:

Rhyme is only a particular, condensed case of a much more general, we may even say the fundamental problem of poetry, namely parallelism ... equivalence in sound, projected into the sequence as its constitutive principle, inevitably involves semantic equivalence, and on any linguistic level any constituent of such a sequence prompts one of the two correlative experiences which Hopkins neatly defines as "comparison for likeness' sake" and "comparison for unlikeness' sake." (ibid.:368, italics in original)

In the case of song, the way musical elements are projected into recurring combination may create "likeness" or "unlikeness" among linguistic elements and vice versa. This is an extension of Jakobson's thesis that parallelism makes sense of the interaction between metre and meaning in poetry (ibid.:369), but in this case applied to song.

The elements of poetic form that intuitively manifest parallelism in a fundamental way are also present in music. The musicologist Leonard Meyer remarks that "style is a replication of patterning, whether in human behaviour or in the artefacts produced by human behaviour, that results from a series of choices made within some constraints" (Meyer 1989:3, italics in original). Meyer's insight evokes Jakobson's thesis regarding selection and combination, suggesting that parallelism is a fundamental part of musical composition and perception.

\section{Parallelism with respect to a musical element or lingual element}

Throughout Kiale's pikono there are numerous instances of parallelism with respect to either a lingual element or a musical element. With respect to a lingual element, consider the passage shown in text $1,{ }^{3}$ in which Kiale lists different praise names referring to bridges. Praise names are series of special words used to describe landscape, animals, feathers, hair, and other significant features. These praise names are not used in everyday speech, may be secret, and are recited in series within Kiale's pikono. ${ }^{4}$

3 San Roque's linguistic transcript and recording is in four volumes. Here and below, the passages I have excerpted are identified by volume number in parentheses, followed by a time code in minutes and seconds, which indicates the time of the extract within that volume as shown in the transcript.

4 Praise names in Duna have been extensively studied by Nicole Haley (2002). Haley's definition of praise names is generally restricted to landscape, flora, and fauna. Other important words are defined by Haley as 
Text 1. Excerpt from linguistic transcription and translation of Kiale's pikono-(vol. 4) 0:13. An audio file of this example can be found in online item 4.

Mm ima ima rayane kititaom

Anene ru aya sokota riya so

Rundu aya sokota riya so

Papi aya sokota riya so
Mm the woman the pair of them went down

The pair returned on the ru ayu bridge

The pair returned on the rundu ayu bridge

The pair returned on the papi ayu bridge

In text 1 , Kiale recites several praise names for bridge - ru aya in line 2, rundu aya in line 3, and papi aya in line 4 . These praise names are framed by the repeated phrase sokota riya so. In this instance, three words form a paradigmatic set referring to bridge - the words ru aya, rundu aya, and papi aya, are placed into relation with one another. The repeating framing phrase aya sokota riya so creates "equivalence" between these praise names, which is projected over time in the syntagmatic axis. This instance of parallelism is an important poetic device in the telling of pikono, particularly with respect to the listing of praise names.

An example of parallelism with respect to musical elements can be found in the repeated types of melodies that occur throughout Kiale's pikono. Gillespie and San Roque (chapter 3) identify what they call the "phrase" as the basic unit in pikono. A phrase usually begins a descending melody (or series of descending melodies) of a musical fifth or sixth towards a tonic note, which Gillespie and San Roque describe as a "descent" and which provides most of the narrative content of the phrase. This is usually followed by a series of melodies based around the tonic note; Gillespie and San Roque describe this as a "ground," which elaborates on the narrative, often by listing praise names.

Figure 1 consists of a consecutive series of six grounds using Gillespie and San Roque's classification. ${ }^{5}$ In this instance, parallelism can be found through the first three grounds corresponding with the last three grounds - the first and fourth grounds both begin on an $\mathrm{E}$ and end on a $\mathrm{C}$; the second and fifth grounds both begin on an $\mathrm{E}$ and end on a $\mathrm{C}$; and the third and sixth grounds both begin on a $\mathrm{D}$ and end on a C. More generally, each ground, through repetition and variation of various musical elements (such as different starting pitches in the above example), is placed in parallel relationships with all the others. In this case, the narrow melodic descents that constitute the grounds comprise a set of paradigmatic musical units. This creates a structural equivalence between the first three grounds and final three grounds (corresponding to the text that refers to a different set of praise names in the first three grounds and the final three grounds, discussed below). The principle of equivalence, through which these descents form a paradigmatic set, is projected onto the axis of combination through their occurrence in the same syntagmatic position within the pikono.

5 The middle staff in figure 1 notates the beat derived from accented syllables. The top staff provides imaginary beats that are more constant for analytical purposes only, as a more regular pulse. The boxed sections refer to the descriptions below of the parallelism of one element causing equivalence in another element (type B). 
Figure 1. Examples of parallelism of musical elements in Kiale's pikono-(vol. 2) 1:50. An audio file of this example can be found in online item 5 .

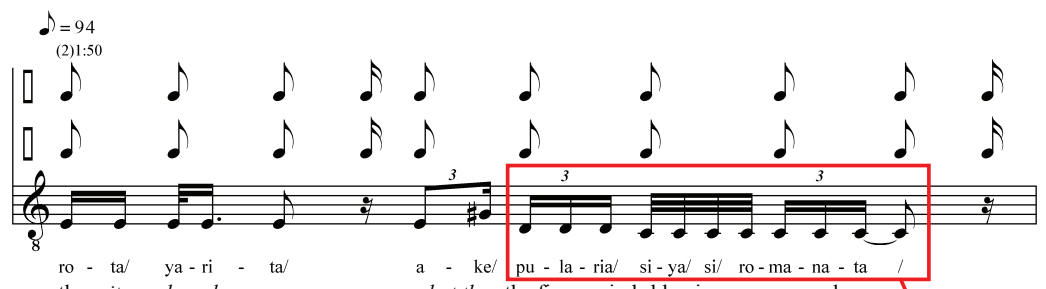

there it was heard

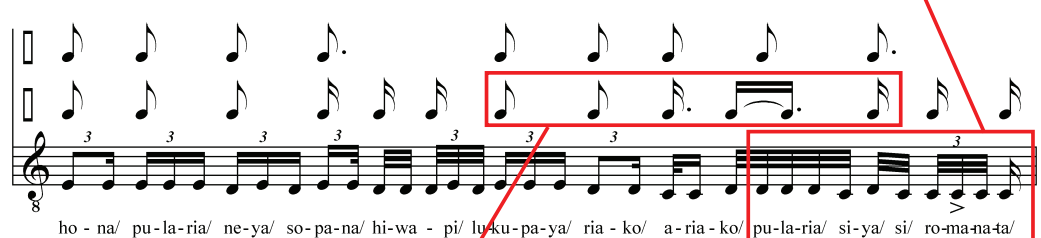
- pa-na/ hi-wa - pi/ly-ku-pa-ya/
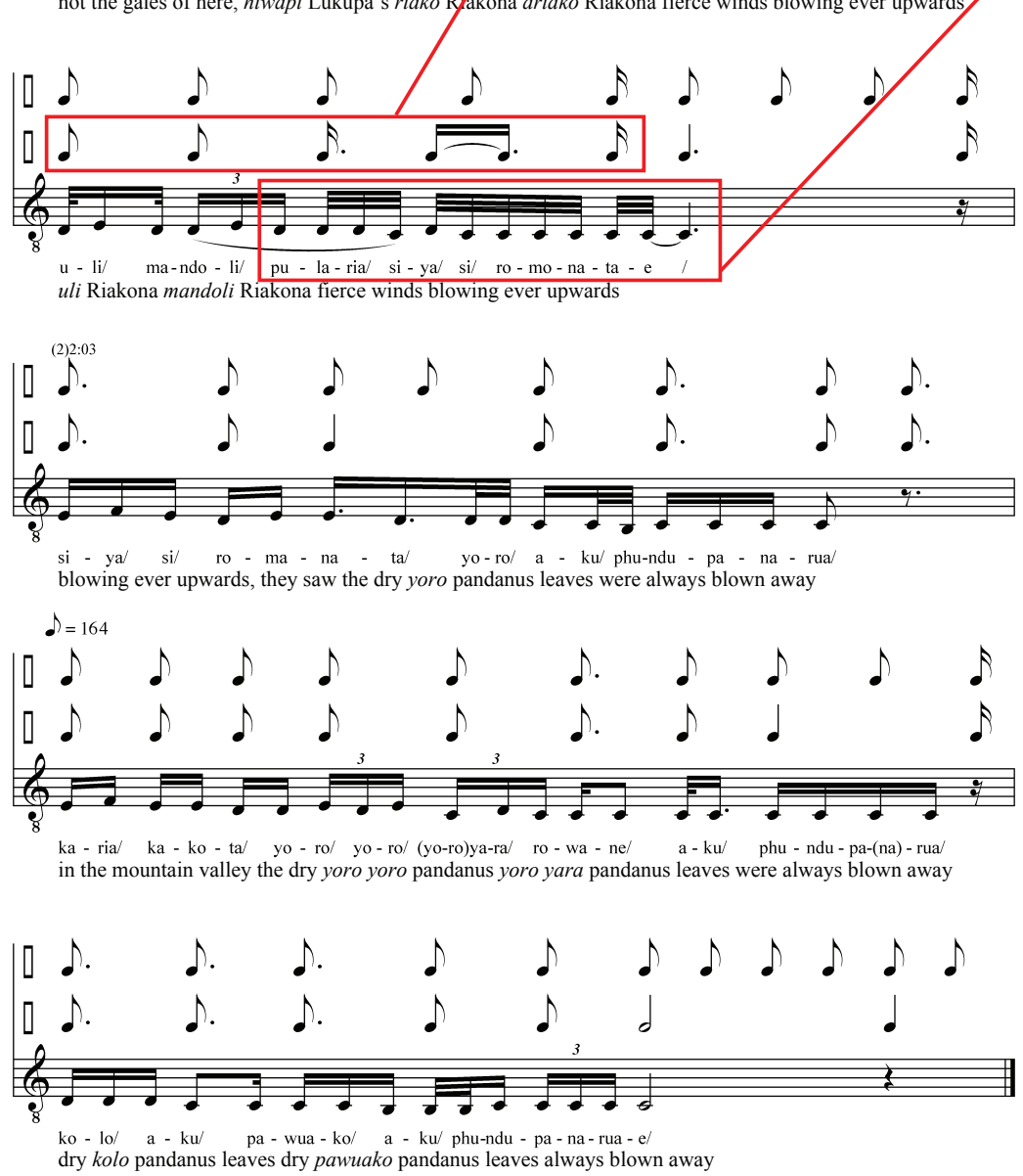
The above examples illustrate how parallelism can operate with respect to either a lingual element or a musical element. However, the performance of song is essentially both lingual and musical, and it can be seen how parallelism operates between musical elements and lingual elements. This happens in two different ways, which will be discussed in the following section.

\section{Parallelism between musical elements and lingual elements}

\section{Type A: A single stretch of sound as both a musical element and lingual element}

Parallelism between a musical element and a lingual element can be seen in two different ways. Firstly, consider the case where a single stretch of sound realizes both a musical element and lingual element. Duna is a tonal language, in which some words are spoken with particular pitch contours that are used to distinguish among semantic meanings, creating "tone-melody." The lingual text that Kiale sings, therefore, implies a particular tone-melody. This tone-melody may not correspond with the pitch contour that is sung - the "tune-melody." The degree of correspondence between the two can be measured as a tunetone correspondence. ${ }^{6}$ In this instance, a single stretch of sound that Kiale sings implicates both a musical element (the pitches that he is actually singing) and a lingual element (the pitches that correspond to the semantic meaning of the lingual text). Semantically distinctive values of pitch are thus mapped out when Kiale sings them.

In September 2006 I worked with two Duna speakers, Kenny Kendoli and Richard Alo, who recited certain lines from Kiale's pikono in a normal speaking voice. ${ }^{7}$ The pitch contours of their phrases were studied using broadband audio spectrographs of the words both in isolation and in sentences, ${ }^{8}$ which were compared to Kiale's sung melodic contour in his pikono. This experiment thus provided scope to analyse the tune-tone correspondence for single words as well as for general intonation over a spoken phrase to see the effects of tone sandhi. ${ }^{9}$

6 The terms "tone-melody," "tune-melody," and "tune-tone correspondence" have been adapted from Leben (1985).

7 These lines were chosen in collaboration with Lila San Roque.

8 For this I made use of the Praat software, which can be obtained from http://www.fon.hum.uva.nl/praat/.

9 Tone sandhi includes the ways in which the tone of a given syllable is affected by its position within a larger utterance due to vocal intonation over the course of the utterance. For example, due to the gradual drop in pitch that tends to occur over the course of an utterance between one breath and the next ("declination"), a word with a rising tone melody may be realized with a level pitch, whereas in the same position within the utterance a word with a level tone-melody would be realized with a falling pitch. 
Figure 2 shows an example of the comparisons between the spoken (in cipher notation above) and sung (in musical notation below) texts. ${ }^{10}$

Figure 2. Comparison between spoken (above, in cipher notation) and sung versions (in musical notation) of the same text-(vol. 1) 18:23. Audio files of this example can be found in online items 6-7. Online item 6 is the spoken text from Kenny Kendoli and Richard Alo; online item 7 is Kiale Yokona singing the same text in performance of pikono.

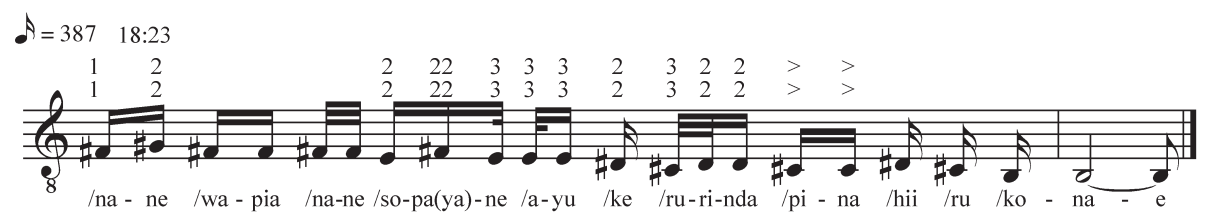

In the example in figure 2, a tune-tone correspondence occurs on the first occurrence of the word nane. The following two words wapia and nane were not included in the spoken version of this line by Kenny and Richard as they make no linguistic sense. The word sopayane is spoken with a rising tone-melody and sung with a rising tune-melody (although the final syllable /ne/ falls to an E, it is relatively short in duration and seems to lead on to the following word $a y u$ ). A tune-tone correspondence continues over the words ayu ke, but a deviation occurs on the word rurinda, where there is a spoken falling tone-melody but a sung rising tune-melody.

A summary of the overall findings is presented in figure 3. Each entry indicates the number of occurrences where a certain tone-melody (on the vertical axis), including tone-sandhi effects, was performed as a certain tune-melody (on the horizontal axis). The number of tune-tone correspondences for each tone-melody is notated in bold along the diagonal axis, with a percentage of total occurrences for each tune-melody indicated below.

Generally, a low tune-tone correspondence was found for falling tone-melodies, and a high correspondence was found for both rising and level tone-melodies. This may be due to the descending melodies commonly sung in pikono. Since there is a general descent across consecutive words in many pikono phrases, maintaining a tune-tone correspondence for falling tone-melodies may cause the sung melody to "descend-too-far." This in part explains the tune-tone deviation

10 The staff notation represents the notes Kiale sings during his pikono. The two series of numbers above the staff represent in cipher notation the relative pitches spoken by Kenny and Richard, respectively, in their spoken version of Kiale's sung text. A " $>$ " represents a strong declination in the spoken version. The words spoken by Kenny and Richard differ slightly from Kiale's sung version to preserve the meaning and linguistic sense of the phrase in a spoken context outside of pikono performance. Kenny and Richard speak the words ayu ipa kuruku ngotine nane sopayane ayu ke rurinda pina. Each speaker says the line slowly word-by-word and repeats the whole line in normal speech; the other speaker then follows the same sequence. The words ayu ipa kuruku ngotine are lacking from the sung version; the latter begins with wapia nane. The sung version also concludes with words not found in the spoken version (hii ru konae). 
that occurred upon the word rurinda in figure 2-in this instance, Kiale was towards the end of his melodic descent, and to descend any further would disrupt the musical form. Here, the musical structure of descending words in a phrase transforms a falling spoken tone-melody into a rising sung tune-melody. ${ }^{11}$

\begin{tabular}{|c|c|c|c|c|}
\hline \multicolumn{5}{|c|}{ Occurences of tune-melody } \\
\hline & rising & falling & level & concave \\
\hline rising & 30 & 1 & 6 & 0 \\
\hline falling & 2 & 4 & 7 & 2 \\
\hline level & 3 & 1 & 8 & 0 \\
\hline concave & 2 & 0 & 1 & 0 \\
\hline \multicolumn{5}{|c|}{ Percentages that a tune-melody occurs for a given tone-melody } \\
\hline & rising & falling & level & concave \\
\hline rising & $81 \%$ & $3 \%$ & $16 \%$ & $0 \%$ \\
\hline falling & $13 \%$ & $27 \%$ & $47 \%$ & $13 \%$ \\
\hline level & $25 \%$ & $8 \%$ & $67 \%$ & $0 \%$ \\
\hline concave & $67 \%$ & $0 \%$ & $33 \%$ & $0 \%$ \\
\hline
\end{tabular}

\section{Figure 3. Distribution of tune-tone correspondence.}

Here we thus see a single stretch of sound realizing a lingual element (tonemelody) and musical element (tune-melody). Words spoken with a falling toneme tend to transform into a level tone-melody when sung, which becomes a characteristic feature of Kiale's pikono. In this instance, a single composite paradigmatic unit (the sung word), simultaneously figures as both a musical element and a lingual element, which both share a phonetic dimension of pitch. A paradigmatic unit in this way figures in relations of parallelism with respect to both a musical element and lingual element. In this instance parallelism between both musical elements and lingual elements may cause an interaction between musical and lingual elements, exemplified by the tune-tone deviations that often occurred over falling tone-melodies. In figure 2, for example, Kiale transforms the word rurinda from a falling spoken tone-melody to a rising sung tune-melody. This deviation represents the combination of a falling tone-melody (linguistic element) and rising tune-melody (musical element) as constituting a paradigmatic unit. This paradigmatic unit is then projected in the same position on the syntagmatic axis in relation to the descent structure of the pikono- the deviation repeats in order for the melody not to "descend-too-far."

11 The analysis of tune-tone correspondence in Duna pikono and the phenomenon of tune-tone correspondence generally can be found in Sollis (2010). 


\section{Type B: Parallelism of one element causing equivalence in another element}

In type B, the parallelism of a musical element can lead to equivalence between lingual elements and vice versa. This occurred many times throughout Kiale's pikono. For instance, in figure 1, the words pularia siya si romanata appear at the end of the first descent describing the fierce winds. There is parallelism between two combined paradigmatic units - the musical sequences of pitches and the linguistic words - which are projected into the axis of combination by framing praise names associated with fierce winds ariako and mandoli in lines two and three. The pitches and words are thus repeated together (with the exception of a raised ya in siya on the second line). This corresponding parallelism between one musical element (pitch) and a lingual element (words) exemplifies a simple level of interplay, where both musical and lingual elements are associated with each other in a constant manner.

By contrast, a complex interplay can be seen to occur in grounds 2 and 3 of figure 1 , between two musical elements (the melody and the rhythm/beat pattern) and a lingual element. This occurs through the repetition of a different paradigmatic unit, in this instance the pattern of musical beats : $: 2$ : that occurs in both the second and third lines. This is associated with the parallelism of the words/ melody. However, the two instances of parallelism are disjunct - they do not directly correspond with each other. The beat pattern - and resulting rhythmic text-setting - is out of phase with the word/melody parallelism that also occurs over these lines. This suggests a degree of independence between various musical and lingual dimensions, and a complex interplay between them, resulting in the disjunct parallelism that is found.

Over the course of Kiale's pikono, there are several instances of a higher-order parallelism, where the semantic equivalence of lingual-elements was projected through the repetition and variation of musical-elements. In one two-minute extract, parallel occurrences of musical elements occurred between sections of the pikono listing praise names of feathers, names of boys, cassowaries, and hair. Interestingly, this corresponds to what we know of Duna cosmology, where there are cultural associations linking feathers, boys, and hair (Stewart and Strathern 2002:149, Haley 2002:149). In this instance, semantic equivalence between praise names for feathers, boys, and hair is projected through parallel occurrences of musical structure.

Such instances of parallelism establish a relationship between musical elements and lingual elements in the performance, such as the simple and complex alignment of different musical elements and linguistic elements shown in figure 1 . Parallelism of a musical element can thus project equivalence of a linguistic element and vice versa. In this way, parallelism between musical elements 
and lingual elements figures as part of broader cultural and social processes by establishing and reproducing cultural relationships - such as that between hair and feathers in Kiale's pikono — and creating a Jakobsonian "equivalence" between them.

The brief analysis above demonstrates several ways in which parallelism operates between lingual elements and musical elements within Kiale's pikono. Through understanding how parallelism works with respect to both language and music, a broader understanding of the interaction between music and language within song can be reached.

\section{References}

Feld, Steven. 1988. "Aesthetics as Iconicity of Style, or 'Lift-up-over Sounding': Getting into the Kaluli Groove.” Yearbook for Traditional Music 20: 74-113.

Haley, Nicole. 2002. "Ipakana Yakaiya: Mapping Landscapes, Mapping Lives; Contemporary Land Politics among the Duna." PhD dissertation, Australian National University.

Jakobson, Roman. 1960. "Closing Statement: Linguistics and Poetics." In Style in Language, edited by Thomas A. Sebeok, 350-77. Cambridge, MA: Massachusetts Institute of Technology Press.

Leben, William R. 1985. "On the Correspondence between Linguistic Tone and Musical Melody." In African Linguistics: Essays in Memory of M. W. K. Semikenke, edited by Didier L. Goyvaerts, 335-43. Studies in the Sciences of Language, 6. Amsterdam: Benjamins.

Meyer, Leonard B. 1989. Style and Music: Theory, History, and Ideology. Philadelphia: University of Pennsylvania Press.

Ruwet, Nicolas. 1987. "Methods of Analysis in Musicology." Music Analysis 6 (1-2): 11-36.

Sollis, Michael. 2007. "Musical-lingual Interplay in a Papua New Guinea Sung Story." Honours thesis, Australian National University.

—. 2010. "Tune-tone Relationships in Sung Duna Pikono." Australian Journal of Linguistics 30: 67-80.

Stewart, Pamela J., and Andrew Strathern. 2002. Gender, Song and Sensibility: Folksongs and Folktales in the Highlands of New Guinea. Westport, CT: Praeger. 